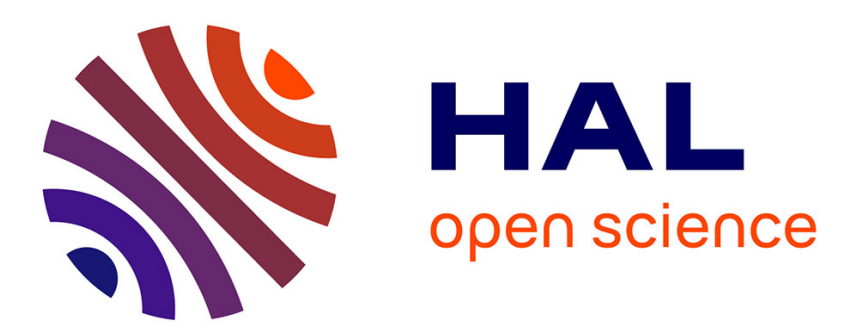

\title{
Effect of Dual Cure Composite as Dentin Substitute on Marginal Integrity of Class II Open-Sandwich Restorations
}

\author{
S Koubi, A Raskin, J Dejou, I About, H Tassery, J Camps, J-P Proust
}

\section{To cite this version:}

S Koubi, A Raskin, J Dejou, I About, H Tassery, et al.. Effect of Dual Cure Composite as Dentin Substitute on Marginal Integrity of Class II Open-Sandwich Restorations. Operative Dentistry University of Washington-, 2009, 34, pp.150 - 156. 10.2341/08-29 . hal-03467891

\section{HAL Id: hal-03467891 \\ https://hal.science/hal-03467891}

Submitted on 6 Dec 2021

HAL is a multi-disciplinary open access archive for the deposit and dissemination of scientific research documents, whether they are published or not. The documents may come from teaching and research institutions in France or abroad, or from public or private research centers.
L'archive ouverte pluridisciplinaire HAL, est destinée au dépôt et à la diffusion de documents scientifiques de niveau recherche, publiés ou non, émanant des établissements d'enseignement et de recherche français ou étrangers, des laboratoires publics ou privés. 


\title{
Laboratory Research
}

\section{Effect of \\ Dual Cure Composite as Dentin Substitute on Marginal Integrity of Class II Open-Sandwich Restorations}

\author{
S Koubi • A Raskin • J Dejou • I About \\ $\mathrm{H}$ Tassery $\bullet \mathrm{J}$ Camps $\bullet J-P$ Proust
}

\begin{abstract}
Clinical Relevance
Dual-curing composites may present a good alternative to RMGIC in open-sandwich restorations and they act as a dentin substitute. However, this study showed that RMGIC remains the best intermediate material when open-sandwich restorations are indicated.
\end{abstract}

\section{SUMMARY}

The current study compared the marginal adaptation of Class II open-sandwich restorations

\footnotetext{
*Stefen Koubi, DDS, Laboratoire IMEB and Department of Operative Dentistry, Faculté d'Odontologie, Université de la Méditerranée, Marseille, France

A Raskin, PhD, Laboratoire IMEB, Faculté d'Odontologie, Université de la Méditerranée, Marseille, France

J Dejou, PhD, Laboratoire IMEB, Faculté d'Odontologie, Université de la Méditerranée, Marseille, France

I About, $\mathrm{PhD}$, Laboratoire IMEB, Faculté d'Odontologie, Université de la Méditerranée, Marseille, France

$\mathrm{H}$ Tassery, PhD, Laboratoire IMEB, Faculté d'Odontologie, Université de la Méditerranée, Marseille, France

J Camps, PhD, Laboratoire IMEB, Faculté d'Odontologie, Université de la Méditerranée, Marseille, France

J-P Proust, PhD, Laboratoire IMEB, Faculté d'Odontologie, Université de la Méditerranée, Marseille, France

*Reprint request: 51 rue de la palud, 13001 Marseille, France; e-mail: koubi-dent@wanadoo.fr

DOI: $10.2341 / 08-29$
}

with a RMGIC versus a dual-cure composite as dentin substitute.

Class II cavities were prepared on 50 extracted human third molars. The teeth were randomly assigned to two groups of 25 teeth to compare one dual cure composite (MultiCore Flow) with one resin-modified glass-ionomer cement (Fuji II LC) in open-sandwich restorations recovered with a light cure composite. The teeth were thermomechanocycled $\left(2000\right.$ cycles, $5^{\circ} \mathrm{C}$ to $55^{\circ} \mathrm{C} ; 100,000$ cycles, $50 \mathrm{~N} / \mathrm{cm}^{2}$ ). The specimens were then sealed with a $1 \mathrm{~mm}$ window around the cervical margin interface. Samples were immersed in a $50 \% \mathrm{w} / \mathrm{v}$ ammoniacal silver nitrate solution for two hours and exposed to a photo-developing solution for six hours. The specimens were sectioned longitudinally and silver penetration was directly measured using a light microscope. The results were expressed as a score from 0 to 3 . The data were analyzed with a non-parametric Kruskal and Wallis test. 
The degree of leakage significantly increased with MultiCore Flow (median 2) compared to Fuji II LC (median 1). Resin-modified glassionomer cements remain the best intermediate material when open-sandwich restorations are indicated. A comparison of the degradation of these materials over time remains a topic to be investigated by future studies.

\section{INTRODUCTION}

Direct Class II restorations are known to show more leakage around enamel ${ }^{1}$ and dentin margins $\mathrm{s}^{2-3}$ than indirect restorations. However, a direct Class II restoration with composite is commonly used in daily practice, as it provides a good aesthetic result at low cost. Unfortunately, several factors account for marginal microleakage when using a composite. The enamel around the proximal box is often of poor quality or is totally absent. Furthermore, some voids within the materials and at the gingival margin have been reported. ${ }^{4}$ Adequate polymerization of the material and, therefore, its clinical success, depend on factors related to the material itself, such as the type of monomer ${ }^{5}$ or its shade, ${ }^{6}$ but clinical success also depends on clinical factors, such as the incremental technique ${ }^{7}$ distance from the light source, ${ }^{8}$ the type of curing unit, ${ }^{9}$ blood ${ }^{10}$ and salivary ${ }^{11}$ contaminations. Together, this renders the Class II restoration technique sensitive to operator skill. ${ }^{12}$

Difficulties with Class II restorations led to the development of open-sandwich restorations-a glassionomer cement (GIC) or a resin-modified glassionomer cement (RMGIC) placed between the dentin gingival margins and occlusal composite restoration. GIC presents two interesting features in restorations by bonding spontaneously to dentin and releasing fluoride. ${ }^{13}$ These sandwich restorations are less sensitive to technique than composite restorations ${ }^{14}$ and show a high percentage of gap-free interfacial adaptation to dentin. ${ }^{15}$ However, despite good short-term clinical results, ${ }^{16}$ a noticeable dissolution of RMGIC was reported after six years. ${ }^{17}$

Dual-curing composites may present a good alternative to RMGIC in open-sandwich restorations and they act as a dentin substitute (Figure 1). Even if a final insulation is necessary to achieve maximal polymerization of the material, ${ }^{18}$ the dual-curing composite can be placed in bulk, such as RMGIC circumventing all of the clinical problems related to light curing. In addition to this clinical advantage over light-curing composites, self-curing composites polymerize more slowly, ${ }^{19}$ resulting in lower polymerization contraction stress. ${ }^{20}$ Moreover, it was reported that flowable materials, such as dual-cure composites, may improve the marginal and internal adaptation of composite restorations. ${ }^{21}$

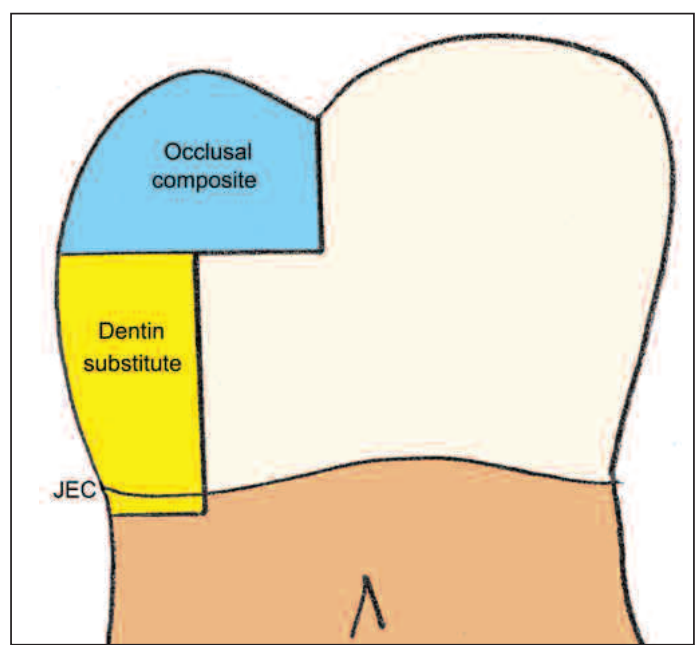

Figure 1. Open-sandwich technique.

To the best knowledge of the authors of the current study, no study has analyzed the effectiveness of opensandwich restoration components. Therefore, the aim of the current study was to compare the marginal adaptation of Class II open-sandwich restorations with an RMGIC versus a dual-cure composite as a dentin substitute.

\section{METHODS AND MATERIALS}

Fifty sound extracted human third molars were collected and any remnant of soft tissue was immediately removed. The teeth were stored in $1 \%$ chloramine $\mathrm{T}$ at $4^{\circ} \mathrm{C}$ until use within two months of collection. Experimental procedures were conducted according to French ethics laws.

\section{Specimen Preparation}

After visual inspection with a light microscope to ensure that the teeth did not present any caries or cracks due to extraction, the teeth were cleaned and polished with scalers and pumice. One standardized mesio-occlusal Class II cavity was prepared on each tooth. All the manipulations and restorations were performed by the same experienced operator to prevent any variation due to operator skill. The operator performed these procedures under 3.5x magnification with fibre optic headlight illumination. The cavities were prepared with a fibre optic, high-speed handpiece T1 (Sirona, Benshein, Germany) using a diamond bur (ISO 6856310023, Komet, Lemgo, Germany) under heavy water spray. A new diamond was used after every five preparations. All internal line angles were rounded. The overall dimensions and depth of the cavities were standardized as follows: occlusal floor: width $4 \mathrm{~mm}$, length $5 \mathrm{~mm}$; axial wall: width $4 \mathrm{~mm}$, height 3 $\mathrm{mm}$; gingival floor: width $4 \mathrm{~mm}$, depth $2.5 \mathrm{~mm}$. The proximal boxes ended in dentin just below the enamelcementum junction (ECJ). The teeth were stored in 
saline and randomly divided in two groups: the test group and the control group, depending on the filling material to be used for the sandwich restoration: Group $1(\mathrm{n}=25)$, MultiCore Flow (Ivoclar Vivadent, Schaan, Liechtenstein) and Group $2(\mathrm{n}=25)$, Fuji II LC (GC Corp, Itabahi-ku, Japan).

\section{Cavity Filling}

Group 1: MultiCore Flow. The preparations were etched with Ultra-Etch 35\% phosphoric acid (Ultradent, South Jordan, UT, USA). The etchant was first placed on enamel using the supplied syringe; it was then applied to the dentin, ensuring that the dentin would only be etched for 15 seconds. A digital timer was used for all the timed procedures. The etchant was rinsed off after 10 seconds. The preparations were dried for five seconds to ensure that the enamel was etched, then re-moistened with Consepsis (Ultradent) to provide a visibly damp tooth surface. All Bond 2 (BISCO, Schaumburg, IL, USA) was used as the dentin/enamel bonding agent and placed as follows. An applicator tip was used to apply the primer for 30 seconds; the primer was continuously applied and agitated but not scrubbed on the tooth. The tooth was then dried with a constant but gentle stream of air for 15 seconds and light-cured for 20 seconds. The adhesive was dispensed, mixed with an applicator for five seconds and applied in the entire cavity. After removing the excess material using the applicator like a sponge, this layer was cured for 30 seconds. All the light-cured and dual-cure materials were polymerized with a bluephase curing light (Ivoclar-Vivadent) using a new 11-mm tip and new light bulb. The curing light was tested before each restoration and measured at least $1600 \mathrm{~mW} / \mathrm{cm}^{2}$ on a curing radiometer (Demetron, Bioggio, Switzerland). An Auto matrix (Dentsply DeTrey, Konstanz, Germany) was placed around the teeth and secured. MultiCore Flow was used in bulk to fill the apical two-thirds of the cavity. The material was allowed to chemically set for four minutes and was then light cured for 40 seconds. The last coronal third was filled with a light-curing composite (Tetric EvoCeram, Ivoclar Vivadent) using an incremental technique. Each increment was light cured for three seconds according to the soft polymerization concept, then cured for 40 seconds. The composite was applied with a special instrument (CVHL1/2, Hu Friedy, Chicago, IL, USA). The fiber optic headlight was turned off during the filling procedures to prevent premature partial polymerization of the light-curing material.

Group 2 Fuji II LC. The smear layer covering the dentin walls was removed using $10 \%$ polyacrylic acid for 20 seconds. After rinsing for 10 seconds, Fuji II LC was prepared according to the manufacturer's recommendations and placed in bulk to fill the apical twothirds of the cavities. Fuji II LC was allowed to chemi-

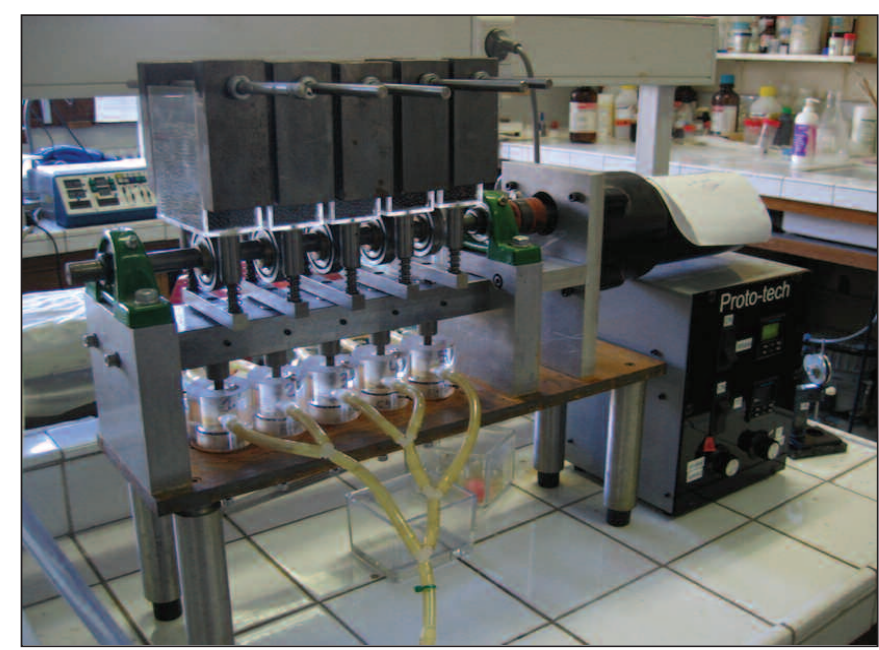

Figure 2. Fatigue-cycling machine.

cally set for five minutes and was then light-cured for 40 seconds. It was not cured immediately to allow for a more accurate comparison with MultiCore Flow, which has dual curing capability. The last coronal third was filled with All Bond 2 and Tetric EvoCeram, as in Group 1.

\section{Thermomechano-cycling}

The teeth underwent thermocycling and mechanocycling using a fatigue cycling machine (Proto-tech, Portland OR, USA) in conjunction with two recirculating water baths: a refrigerated bath (Merlin 33, Thermo Neslab, New Ington, NH, USA) and a heating bath (Isotemp 3016H, Fisher Scientific, Pittsburgh, PA, USA). A peristaltic water pump was used to return water from the teeth towards the baths. These four devices were connected to a four-way solenoid valve. The bath temperatures were self-regulated, the dwell time commanded by the solenoid valve and the mechanical parameters were under the control of the fatigue cycling machine (Figure 2).

The teeth were mounted into acrylic potting rings, and the roots of the specimens were partly embedded in epoxy resin (Buehler, Lake Bluff, IL, USA) to secure the teeth. A guide rod, representing the stylus of the fatigue cycler, was used to adjust the specimen position so that the guide rod touched the restoration exactly where the round ended stylus was to be placed during mechanocycling - in the center of the occlusal composite restoration.

The acrylic rings containing the teeth were placed 5 by 5 in the mechanocycling device and secured, and the other teeth were stored in PBS at $4^{\circ} \mathrm{C}$. The loading device delivered an intermittent axial force of $50 \mathrm{~N}$ at 2 Hzs for a total of 100,000 cycles. The dwell time was set at 20 seconds and the temperatures were $10^{\circ} \mathrm{C}$ and $50^{\circ} \mathrm{C}$. 


\section{Silver Nitrate Penetration Study}

The teeth were coated with two layers of red nail varnish, with $1.0 \mathrm{~mm}$ left around the margins of the cavity. Teeth were immersed in a 50\% (w/v) solution of silver nitrate for two hours, rinsed in distilled water for five minutes, placed in a photo-developing solution (Ilford ID 11, Mobberley, Cheshire, England) for six hours under fluorescent light and rinsed with distilled water for five minutes. Each tooth was enrobed in an epoxy resin (Sody 33, Escil, Chassieu, France). The teeth were sectioned mesio-distally with a diamond saw (Buehler) under copious water coolant. Three different sections per tooth were obtained, leaving six faces for examination of dye penetration under a light microscope at 25x magnification. Another operator, who was blinded to the study, performed the observations. The intra-operator consistency had been verified in pre-

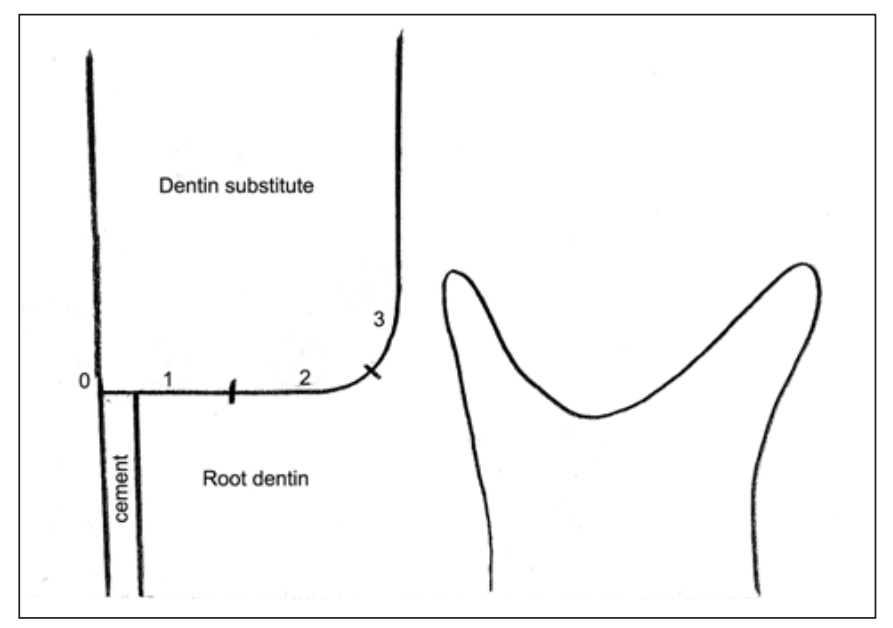

Figure 3. Scores of the leakage.

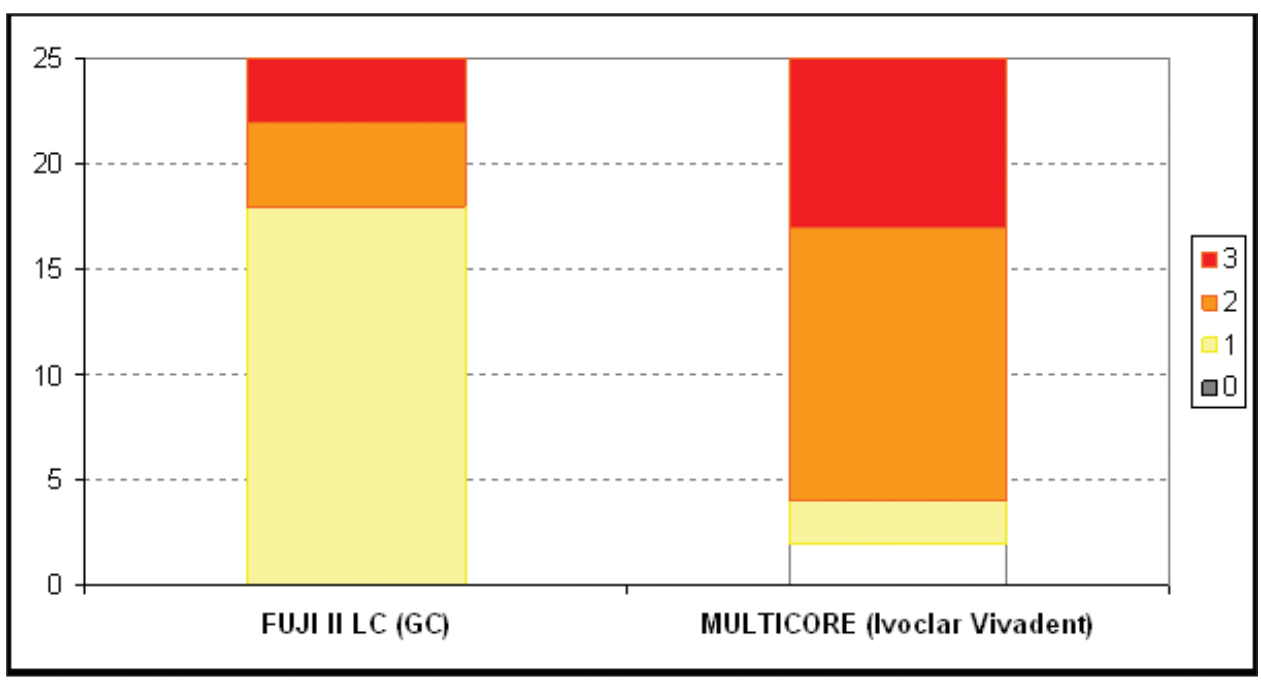

Figure 4. Silver nitrate penetration scores of two open-sandwich restorations. Teeth restored with Fuji II $L C$ presented a statistically significantly $(\mathrm{p}=0.001)$ lower score than those restored with MultiCore. vious studies. The leakage was scored as follows: $0=$ no dye penetration, 1 = dye penetration to one-half of the gingival floor, 2 = dye penetration to more than one-half of the gingival floor and $3=$ dye penetration to the axial wall (Figure 3). The highest score of the six faces from each specimen was recorded.

\section{Controls}

Ten additional teeth, similar to those in Group 1, were prepared for use as the controls. The negative controls $(n=5)$ were fully covered with two layers of varnish, instead of leaving $1 \mathrm{~mm}$ free around the margins of the restorations. The positive controls $(\mathrm{n}=5)$ did not receive any dentin-bonding agent between the dentin walls and MultiCore Flow.

\section{Statistical Analysis}

The scores of the two groups were compared using a Kruskal-Wallis non-parametric test.

\section{RESULTS}

Dye penetration was significantly higher $(p=0.001)$ in Group 1, restored with MultiCore Flow (median 2), than in Group 2, restored with Fuji II LC (median 1) (Figure 4). The negative controls did not show any silver penetration (median 0 ) and high penetration was observed in the positive controls (median 3).

\section{DISCUSSION}

The results of this in vitro study showed that MultiCore Flow exhibited higher microleakage than Fuji II LC when used as a dentin substitute in opensandwich restorations on human molars. However, none of the materials was able to prevent silver nitrate infiltration within the dentin-material interface. It must be noted that the gingival margins were placed below the CEJ and that the outcome of the study may be more favorable with the use of enamel margins.

Microleakage has been implicated as a cause of postoperative sensitivity $^{22}$ and as one of the mechanisms by which secondary caries may occur. ${ }^{23}$ Therefore, it is important for restorations to be placed in a manner that reduces or even eliminates any gap between the dentin margins and the material. This is why many reports have addressed microleakage, even if the clinical relevance of the topic is still debated. ${ }^{24}$ The protocol used in the current study used sophisticated mechanical loading associated with thermocycling to repro- 
duce, at best, clinical conditions. Both parameters do not occur separately in the oral cavity, and their simultaneous use is a step towards better simulation of oral conditions. Thermocycling is commonly used and has been shown to modify the outcome of microleakage studies. ${ }^{25}$ Some studies questioned its use, showing no difference in microleakage with or without thermocycling ${ }^{26}$ but none have associated thermocycling with mechanical loading. Mechanical loading has been shown to increase the marginal leakage of composite restorations. ${ }^{27}$ The machine used in the current study to simulate occlusal loading was similar to the technology currently used to assess resistance to the oral wear of composites. ${ }^{28}$ Flexural loading is applicable when testing Class V cavities, ${ }^{29}$ and axial loading was performed in the current study as Class II restoration was evaluated. The parameters of occlusal loading were adjustable. The authors of the current study used a 50 $\mathrm{N}$ force, which corresponds to in vivo conditions on natural teeth when clenching in centric occlusion. ${ }^{30}$ The specimens underwent 100,000 mechanocycles and 1,250 thermocycles within approximately 14 hours.

Microleakage at the dentin-Fuji II LC interface has already been tested mainly for Class $\mathrm{V}$ cavities, as this is the primary indication of this material. Despite its clinical implications, few studies have evaluated the marginal integrity of the dentin-Fuji II LC interface when this acts as an intermediate material in opensandwich restorations. The results of the current study corroborate previous investigations that had shown Fuji II LC as providing a better dentinal seal than compomers $^{31}$ and self-curing composites ${ }^{32}$ and is less sensitive than composites to parameters, such as temperature and relative humidity. ${ }^{14}$ In addition, and consistent with the current study, none of the previously tested materials was able to prevent microleakage.$^{33}$ No study has reported on the marginal integrity obtained when using a dual-cure composite. MultiCore Flow is generally used to build-up restorations on pulpless teeth with a fiber post, and in the current case, microleakage is not of primary importance, since a crown is placed afterwards. When used on vital teeth, dual-cure composites are generally used as cement to set indirect restorations, and they are not used as restorative material. The poor results obtained with MultiCore Flow should be considered preliminary results and needs to be confirmed with further studies.

The underlying phenomena driving microleakage, such as capillarity, diffusion and osmotic pressure, remain unclear, but the improvements obtained with RMGIC may stem from their physical and mechanical properties. Resistance to mechanical stress involves a static or dynamic creep, which is a manifestation of the visco-elastic properties of the material. ${ }^{34}$ Since both tested materials acted as a dentin substitute and were covered with composite, their deformation behavior under mechanical stress was likely not an important factor. The results of the current study confirm the idea that composite materials may simultaneously present lower creep values than $\mathrm{RMGIC}^{34}$ but higher microleakage. Therefore, other parameters must be taken into account to explain the results of the study. Elastic modulus describes the relative stiffness of a material within the elastic range. Natural hard tissues, such as dentin, have a range of intrinsic modulus values ${ }^{35}$ and the addition of restorative materials of different moduli may affect the overall stiffness of the restored tooth and generate interfacial stresses. The direct core build-up materials, such as MultiCore Flow, have an elastic modulus of approximately $6 \mathrm{Gpa}^{36}$ and Fuji II LC 10 $\mathrm{Gpa},{ }^{37}$ while that of dentin is approximately $17 \mathrm{Gpa}^{35}$ However, this difference is not sufficient to explain the outcome of the study. In fact, the data obtained from the dental literature are laboratory values that do not account for oral condition simulations. The elastic modulus of Fuji II LC was recently demonstrated to decrease in a damp environment ${ }^{38}$ and with temperature,${ }^{39}$ indicating that in vitro conditions must simulate the oral environment as closely as possible and support the rigorous protocol used in the current study. It has previously been shown that Fuji II LC expanded more in a damp environment than dual-cure resin composites that are used to build-up cores similar to MultiCore Flow. ${ }^{40}$ The tendency of RMGIC to be influenced by exposure to water is well known. ${ }^{41}$ Since both materials are equally affected by the $\mathrm{C}$ factor, ${ }^{42-43}$ this suggests that the good results obtained with Fuji II LC in the current study may be due to water sorption that relieves setting shrinkage. ${ }^{44}$

\section{CONCLUSIONS}

Under the conditions of the current study, RMGIC remains the best intermediate material when opensandwich restorations are indicated. A comparison of the degradation of these materials over time remains a topic for investigation in future studies.

(Received 4 March 2008)

\section{References}

1. Duquia Rde C, Osinaga PW, Demarco FF, de V Habekoat L \& Conceicao EN (2006) Cervical microleakage in MOD restorations: In vitro comparison of indirect and direct composite Operative Dentistry 31(6) 682-687.

2. Alavi AA \& Klanimanesh N (2002) Microleakage of direct and indirect composite restorations with three dentin bonding agents Operative Dentistry 27(1) 19-24.

3. Fruits TJ, Knapp JA \& Khalotia SS (2006) Microleakage in the proximal walls of direct and indirect posterior resin slot restorations Operative Dentistry 31(6) 719-727. 
4. Korkmaz Y, Ozel E \& Attar N (2007) Effects of flowable composite lining on microleakage and internal voids in Class II composite restorations The Journal of Adhesive Dentistry $\mathbf{9}$ 189-194.

5. Charton C, Falk V, Marchal P \& Colon P (2007) Influence of $\mathrm{Tg}$, viscosity and chemical structure of monomers on shrinkage stress in light-cured dimethacrylate-based dental resins Dental Materials 23 1447-1459.

6. Shortall AC, Palin WM \& Burtscher P (2008) Refractive index mismatch and monomer reactivity influence composite curing depth Journal of Dental Research 87 84-88.

7. Attar N, Turgut MD \& Güngör HC (2004) The effect of flowable resin composites as gingival increments on the microleakage of posterior resin composites Operative Dentistry 29(2) 162-167.

8. Rode KM, Kawano Y \& Turbino ML (2007) Evaluation of curing light distance on resin composite microhardness and polymerization Operative Dentistry 32(5) 571-578.

9. Uhl A, Sigush BW \& Jandt K (2004) Second generation LEDs for the polymerisation of biomaterials Dental Materials 20 80-87.

10. Eiriksson SO, Pereira PN, Swift EJ, Heymann HO \& Sigurdsson A (2004) Effects of blood contamination on resinresin bond strength Dental Materials 20 184-190.

11. Hitmi L, Attal JP \& Degrange M (1999) Influence of timepoint of salivary contamination on dentin shear bond strength of 3 dentin adhesive systems The Journal of Adhesive Dentistry 1 219-232.

12. Giachetti L, Scaminaci Russo D, Bertini F, Pierleoni F \& Nieri M (2007) Effect of operator skill in relation to microleakage of total-etch and self-etch bonding systems Journal of Dentistry 35 289-293.

13. Saiot S, Tosaki S \& Hirota K (1999) Characteristics of glassionomer cements in Advances in Glass Ionomer Cements Davidson CL \& Mjör IA pp 15-50 Quintessence Publishing Co, Carol Stream, IL, USA.

14. Besnault C \& Attal JP (2003) Simulated oral environment and microleakage of Class II resin-based composite and sandwich restorations American Journal of Dentistry 16 186-190.

15. Anderson-Wenckert IE, van Dijken JW \& Hörsted P (2002) Modified Class II open-sandwich restorations: Evaluation of interfacial adaptation and influence of different restorative techniques European Journal of Oral Sciences 11 270-275.

16. Vilkinis V, Hörsted-Bindslev P \& Baelum V (2000) Two-year evaluation of Class II resin-modified glass ionomer cement/composite open-sandwich and composite restorations Clinical Oral Investigations 4 133-139.

17. Anderson-Wenckert IE, van Dijken JW \& Kieri C (2004) Durability of extensive Class II open-sandwich restorations with a resin-modified glass ionomer cement after 6 years American Journal of Dentistry 17 43-50.

18. Tanoue N, Koishi Y, Atsuta M \& Matsumura H (2003) Properties of dual-curable luting composites polymerized with single and dual curing modes Journal of Oral Rehabilitation 30 1015-1021.

19. Truffier-Boutry D, Demoustier-Champagne S, Devaux J, Biebuyck JJ, Mestdagh M, Larbanois P \& Leloup G (2006) A physico-chemical explanation of the post-polymerization shrinkage in dental resins Dental Materials 22 405-412.
20. Geng L \& Suh BI (2006) The effect of curing modes on polymerization contraction stress of dual cured composite Journal of Biomedical Materials Research Part B Applied Biomaterial 76 196-202.

21. Li Q, Jepsern H, Albers K \& Eberhard J (2006) Flowable materials as an intermediate layer could improve the marginal and internal adaptation of composite restorations in Class V cavities Dental Materials 22(3) 250-257.

22. Pashley DH, Pashley EL, Carvalho RM \& Tay FR (2002) The effects of dentin permeability on restorative materials Dental Clinics of North America 46 211-245.

23. Mjör IA \& Toffenetti F (2000) Secondary caries: A literature review with case reports Quintessence International 31 165179.

24. Amaral FL, Colucci V, Palma-Dibb RG \& Corona SA (2007) Assessment of in vitro methods used to promote adhesive interface degradation: A critical review Journal of Esthetic and Restorative Dentistry 19 340-353.

25. Nalcai A \& Ulusoy N (2007) Effects of thermocycling on microleakage of resin composites polymerized with LED curing techniques Quintessence International 38 433-439.

26. Li H, Burrow MS \& Tyas MJ (2002) The effect of thermocycling regimens on the nanoleakage of dentin bonding systems Dental Materials 18 189-196.

27. Campos PE, Sampaio Filho HR \& Barceleiro Mde O (2005) Occlusal loading evaluation in the cervical integrity of Class II cavities filled with composite Operative Dentistry 30(6) 727-732.

28. Ferracane JR \& Condon JL (1999) In vitro evaluation of the marginal degradation of dental composites under simulated occlusal loading Dental Materials 15 262-267.

29. Minakuchi S, Munoz CA \& Jessop N (2005) Effect of flexural load cycling on microleakage of estended root caries restorations Operative Dentistry 30(3) 234-238.

30. Richter EJ (1995) In vivo vertical forces on implants The International Journal of Oral \& Maxillofacial Implant 10 99108.

31. Loguercio AD, Bauer JR, Reis A, Filho LE \& Busato AL (2002) Microleakage of a packable composite associated with different materials Journal of Clinical Dentistry 13 111-115.

32. Hagge MS, Lindemuth JS, Mason JF \& Simon JF (2001) Effect of four intermediate layer treatments on microleakage of Class II composite restorations General Dentistry 49489 495.

33. Beznos C (2001) Microleakage at the cervical margin of composite Class II cavities with different restorative techniques Operative Dentistry 26(1) 60-69.

34. El Hejazi AA \& Watts D (1999) Creep and visco-elastic recovery of cured and secondary-cured composites and resin-modified glass-ionomers Dental Materials 15 138-143.

35. Jantarat J, Palamar JE, Lindner C \& Messer HH (2002) Time-dependent properties of human root dentin Dental Materials 18 486-493.

36. Combe EC, Shaglouf AMS, Watts DC \& Wilson NHF (1999) Mechanical properties of direct core build-up materials Dental Materials 15 158-165.

37. Cattani-Lorente MA, Dupuis V, Payan J, Moya F \& Meyer JM (1999) Effect of water on the physical properties of resinmodified glass ionomer cements Dental Materials 15 71-78. 
38. Wang XY, Yap AUJ, Ngo HC \& Chung SM (2007) Environmental degradation of glass-ionomer cements: A depth-sensing microindentation study Journal of Biomedical Materials Research Part B, Applied Biomaterials 82B 1-6.

39. Helvatjioglu-Antoniades M, Papadogiannis Y, Lakes RS, Palaghias G \& Papadogiannis D (2007) The effect of temperature on viscoelastic properties of glass ionomer cements and compomers Journal of Biomedical Materials Research Part B, Applied Biomaterials 80 460-467.

40. Chutinan S, Platt JA, Cochran MA \& Moore BK (2004) Volumetric dimensional change of six direct core materials Dental Materials 20 345-351.

41. Sidhu SK, Sherriff M \& Watson TF (1997) The effects of maturity and dehydratation shrinkage on resin-modified glass-ionomer restorations Journal of Dental Research $\mathbf{7 6}$ 1495-1501.
42. Moreira da Silva E, dos Santos GO, Guimaraes JG, Barcellos Ade A \& Sampaio EM (2007) The influence of C-factor, flexural modulus and viscous flow on gap formation in resin composite restorations Operative Dentistry 32 356-362.

43. Kim YG \& Hirano S (1999) Setting shrinkage and hygroscopic expansion of resin-modified glass-ionomer in experimental cylindrical cavities Dental Materials 18 63-75.

44. Feilzer AJ, Kakaboura AI, de Gee AJ \& Davidson CL (1995) The influence of water sorption on the development of setting shrinkage in traditional and resin-modified cements Dental Materials 11 186-190. 